\title{
Under-achievement and the glass ceiling: Evidence from a TV game show ${ }^{*}$
}

Robin M. Hogarth, ICREA \& Universitat Pompeu Fabra, Barcelona, Spain

Natalia Karelaia, INSEAD, Fontainebleau, France

Carlos Andrés Trujillo, Universidad de los Andes, Bogotá, Colombia

robin.hogarth@upf.edu

natalia.karelaia@insead.edu

$\underline{\text { cat } @ \text { adm.uniandes.edu.co }}$

May 7, 2009

\footnotetext{
* The authors' names are listed alphabetically. They thank Carolina Barrios Laborda and Catalina Estrada for their help in collecting and coding the data, as well as for their comments during the early stages of this research. The authors also thank RCN TV, and in particular Lucas Khapaz, for granting access to the show recordings.
} 


\begin{abstract}
We use a Colombian TV game show to test gender differences in competitive behavior where there is no opportunity for discrimination and females face no genderspecific external constraints. Each game started with six contestants who had to answer general knowledge questions in private. There were five rounds of questions and, at the end of each, one participant was eliminated. Despite equality in starting numbers, women earn less than men and exit the game at a faster rate. In particular, there are more voluntary withdrawals by women than men. We draw an analogy between the game and the process by which employees rise through the levels of a corporation. As such, we note that "glass ceilings" may result, in part, from women's own behavior and this raises the issue of how women are socialized to behave. At the same time, our results illustrate that maintaining and promoting gender diversity at the lower/middle ranks of organizations is necessary to obtain gender diversity at the top.
\end{abstract}

Keywords: discrimination, TV game shows, gender differences, glass ceilings.

JEL classification: C93, D03, E24. 
Today, gender equality is an important issue. For too long, it has been argued, society has ignored or suppressed the potential contributions of females in business, the arts, science, and politics, and this has resulted in two major costs. First, the aspirations of a huge fraction of society have been frustrated. Second, society has failed to profit fully from the potential contributions of women.

Despite legislation aimed at gender equality, the fact remains that male-female wage disparities are still large (Wood, Corcoran, \& Courant, 1993; Blau \& Kahn, $2000^{1}$ ). Moreover, there are few women in top jobs. In 2005, for example, women accounted for $46.5 \%$ of the U.S. workforce but less than $8 \%$ of its top managers. ${ }^{2}$ Moreover, in a study published in 2001, only $2.5 \%$ of the five highest paid executive positions in a large sample of U.S. firms were held by women (Bertrand \& Hallock, $2001^{3}$ ). In politics, the situation is not much better. True, there are many elected female representatives in different countries and quite a few head ministries. Nonetheless, women are still in the minority in terms of power and few become head of state. Angela Merkel in Germany is a current exception.

There are basically two ways of promoting gender equality. One is through legislation and the other by creating new social norms and attitudes (and thus behavior). However, both are imperfect. The former can be mandated immediately but may not be effective in practice; the latter is effective but hard to implement. Many would argue that, in an ideal world, legislation would not be necessary and, instead, gender equality would simply reflect societal norms.

\footnotetext{
${ }^{1}$ Blau and Kahn (2000) report that in the US, the female-male weekly earnings ratio of full-time workers was $76.3 \%$ in $1994-98$.

2 "Women in business", The Economist, July $21^{\text {st }}, 2005$.

3 The authors report that the number of female executives was steadily increasing in larger U.S. corporations in the 1990s. However, there is no evidence that women are gaining access to the top occupational group (CEOs, Chairs, Vice Chairs, and Presidents). In fact, in Bertrand and Hallock's (2001) data, the proportion of women in this group was declining.
} 
The advent to positions of power in society by women is, of course, a recent phenomenon. Thus, we should not exclude the importance of how women have been socialized in the past. For example, if - from one day to the next - we could rid society of gender inequality, would women still defer to men? This is an important question for social policy. If the answer is negative, much more could be achieved through legislation. However, a positive answer would mean that women's current attitudes and behavior are themselves obstacles to gender equality and become selffulfilling prophecies. In other words, it may not be just the attitudes and norms of men that need to be changed, but the very attitudes and norms of women themselves. Perhaps women also contribute to "glass ceilings"?

This paper reports a novel empirical investigation of this issue. We analyze the behaviors of men and women in a TV game show. In the game, contestants earn money by answering general knowledge questions across five rounds and must decide, at the end of each round, whether to stay in the game or leave. If they leave, contestants keep the money earned for correct answers; however, if they fail to leave and turn out to have the lowest "score" of the remaining contestants, they are expelled from the game and lose all their earnings. The game starts with six contestants and at least one contestant leaves voluntarily or is expelled at the end of each of five rounds. At the end of five rounds, the overall winner emerges. Note that in this game, the rules make no distinctions between men and women. Thus, if gender differences emerge, they are a consequence of abilities, attitudes, and behaviors that contestants themselves bring to the game.

This paper is organized as follows. In the next section, we review briefly the literature on the economic analysis of game shows and comment on gender differences in risk attitudes and competitiveness. This is followed by a detailed 
description of the game that we analyzed. Next we present the specific hypotheses of this research and the results of our analysis. In short, although our games start with approximately equal numbers of male and female contestants, we find that women earn less than men and exit the game at a faster rate. In particular, there are more voluntary withdrawals by women than men. We conclude by drawing an analogy between the game and the process by which employees rise through the levels of a corporation except that the game is free of many constraints that women typically face in life. Our results, then, suggest that one reason for "glass ceilings" lies in women's own behavior. This, in turn, probably reflects how they have been socialized. Finally, our results illustrate that maintaining and promoting gender diversity at the lower/middle ranks of organizations is necessary to obtain gender diversity at the top.

\section{Game shows and gender differences}

There should be little surprise that TV game shows have attracted the attention of researchers interested in how people take risky decisions. From a research perspective, there are several advantages and disadvantages. For the former, one can highlight that the games involve real and, often, substantial payoffs; participants come from a wide public that is more general than the mainly student participants recruited for experiments in psychology and economics; and many choices faced by participants should depend on explicit probabilistic reasoning. On the other hand, the games involved can be quite hard to model using traditional economic analysis, and the public nature of the "entertainment" probably has some effects on the type of people who participate as well as on their actual behavior during the game.

Many papers have used the games to elicit risk attitudes in the presence of substantial payoffs (see, e.g., Beetsma \& Schotman, 2001; Blavatsky \& Pogrebna, 
2008; Gertner, 1993; Metrick, 1995; Post, van den Assem, Baltussen, \& Thaler, 2008). In an illuminating review of this work, Andersen, Harrison, Lau, and Rutström (2008) point out the methodological difficulties researchers face in doing this and make some constructive suggestions. Risk attitude, however, has not been the only topic. Pogrebna (2008), for example, has investigated whether contestants who have an opportunity to seek advice from the audience are influenced by the advice. They find that they are not.

From our perspective, a study by Larkin and Pines (2003) is of special interest because they document significant difference between male and female participants in game shows. Specifically, compared to males, the latter consider going on shows to be more personally risky and have more concerns about appearing badly in public. Indeed, in some shows women are a distinct minority. Other researchers have documented gender related differences in risk attitudes and performance. Women have been seen to take less risk than men (Daghofer, 2007; Mulino, Scheelings, Brooks, \& Pfaff, 2006) and to earn less (Johnson \& Gleason, in press).

In the work place, the most cited reasons for the lack of women in upper level management are discrimination, preference differences related to child rearing, and more recently, gender differences in preferences for performing in competitions.

Gender discrimination has been extensively documented both with laboratory and field data. Evidence suggests that women are generally less likely to be promoted than males, and if they are promoted, they have stronger performance ratings than males (Lyness \& Heilman, 2006). That is, women are held to stricter standards for promotion and, to be considered eligible for high leadership positions, have to be more impressive than men. Even minor gender bias in performance evaluation can trigger dramatic gender gaps at the top level of an organization. Simulations show that 
a small gender bias that explains only $1 \%$ of the variance in work performance evaluations suffices to generate significant gender differences in the rate of career advancement (Martell, Lane, \& Emrich, 1996).

The evidence for gender differences in preferences for competitions has been mainly experimental. In a series of controlled experiments, Gneezy, Niederle, and Rustichini (2003) showed that men and women differ in their "drive" to perform well in mixed-sex competitive environments. Men's performance increases with the competitiveness of the environment, thereby creating a gender gap in performance in winner-takes-all contests. Similarly, Niederle and Vesterlund (2007) provide experimental evidence that, when given the choice, men as opposed to equally skillful women, self-select more into competitive as opposed to non-competitive compensation schemes.

In a recent study, Gneezy, Leonard, and List (2008) emphasized the importance of socialization in gender preferences by comparing preferences for selecting into competitive environments by members of the patriarchal Maasai (in Tanzania) with those of the matrilineal Khasi (in India). Whereas Maasai men chose competitive environments more often than Maasai women, Khasi women chose competitive environments more often than Khasi men. From early childhood, men and women are taught appropriate societal behavior for their gender. The learned gender stereotypes affect thoughts and motivations as well as guide behavior (e.g., Martin \& Halverson, 1981; Martin, Wood, \& Little, 1990). Moreover, deviations from expected behaviors sometimes backlash. For example, Bowles, Babcock, and Lai (2007) showed that gender differences in the general tendency for males to initiate negotiations more than females can be explained by the negative reactions women experience when they initiate negotiations. 
Literature on gender differences in negotiations (for a review, see Kray \& Thompson, 2005) also suggests that performance is linked more to pay in the heads of men than women and that, in competitive tasks, whereas males orient themselves more to the impersonal task of maximizing earnings, women demonstrate a greater concern for relationships (Rubin \& Brow, 1975; Kray \& Thompson, 2005). In addition, compared to women, men engage more in "intentional" information use (Deal, 2000).

In our data, discrimination, preference differences related to child rearing, and differences in preferences for competing can be ruled out as explanations for gender effects. First, the proportion of men and women is approximately the same at the beginning of the game and decisions to stay or withdraw from the game are taken individually and independently by each contestant. Second, child rearing is not in conflict with the "job" of participating in the game. Third, women were aware of the competitive nature of the game when they decided to become contestants in the first place.

\section{The game}

We analyzed the first season of a game called "El Ganador" ("The Winner") that was broadcast in Colombia by RCN TV in the first trimester of 2007. It is important to specify that all episodes of this new game were recorded before any broadcasts were made so that no contestant had any specific knowledge about the game before participating in it. Thus, since the game was new to all contestants, there was no confounding effect of differential knowledge. ${ }^{4}$

\footnotetext{
${ }^{4}$ In fact, the game has only been broadcast twice: once, the initial version that we analyze, and secondly in a celebrity version.
} 
Participants were recruited by channel personnel that traveled to major cities in Colombia. Public announcements of a new competitive game were made locally using regular media, and the channel personnel interviewed those who attended the recruitment meetings. There was no attempt to have a random sample of the Colombian population. Instead, the organizers developed a set of criteria to select contestants with a view to establishing a pool of literate, heterogeneous people, with at least a middle level income, inclined to take risks. Contestants varied in age between 18 and 65 (median of 30) and, in terms of occupation, could be classified as students $(21 \%)$, professionals $(69 \%)$, and others $(10 \%)$. Of the 216 contestants, 102 $(47 \%)$ were women. The organizers selected people such that women and men were similarly represented. We did not have access to how many women and men responded to the recruiting announcements. Based on the selection criteria, the female contestants on the show were probably more extraverted and risk-seeking than the average women in Colombia.

The game was based on answering general knowledge questions. We distinguish between three sets of games. The first were "regular" games broadcast each day from Monday through Saturday for six consecutive weeks. Thus there were 36 different regular games. The winner of each regular game (Mondays through Saturdays) participated in a "Sunday" game with the other winners from the same week. Thus there were 6 different Sunday games. Finally, the six winners of these Sunday games played in a grand final game at the end of the season. Given that the stakes were a lot higher in the single, grand final game, we limit our analysis in what follows to the 36 regular and six Sunday games (exceptions are explicitly indicated).

Prior to starting each game, there is a meeting of the six contestants where they introduce themselves to each other and may engage in strategic behavior. For 
example, during this presentation they may tell the truth or lie. (In the broadcasts, it is shown on-screen whether they are lying or not). Contestants are also asked privately how "strong" they perceived the others to be based solely on that first encounter.

Each game consists of five rounds of general knowledge questions (eight questions in the first round and six in each of the subsequent rounds). From the perspective of each contestant, all questions are asked publicly but answered privately using an individual screen. Correct answers are rewarded with monetary values that increase across rounds.

After each round, contestants are ranked according to the money they have accumulated up to that point in the game. Also, after each round they have to decide whether to stay or withdraw from the game. If a contestant withdraws, s/he can keep her/his accumulated prize money. If nobody withdraws, the last contestant in the rankings is expelled and loses all of her/his accumulated prize money. Ties are broken using the time contestants took to answer. (Faster is better). The decision to withdraw is made by pushing a special button.

Contestants are allowed and encouraged to interact publicly after each round of questions in order to gain strategic advantages (e.g., by bluffing). The host asks questions about performance and opinions and contestants may say whatever they want. There is no sure way for the participants to figure out who was lying and who was not. These interactions were very active and took a significant amount of the game time. We were able, therefore, to observe and code types of behavior for all participants in each round. The following are some examples of contestant interactions:

"I did great in this round. Questions were very simple!"

"I feel extremely confident." 
"You (addressing other contestant) seem very upset; you should leave before losing everything, because I am doing great!"

"You clearly seem to ignore all these topics, leave while you can."

"Be sure that I am not withdrawing, believe me, you better push that button."

Finally, the game show host gives the contestants a 10-second warning before the withdrawal button needs to be pushed. During these ten seconds, the contestants can also behave strategically by addressing comments to their competitors.

During the game participants don't know their own rank. The only feedback each receives is her/his number of correctly answered questions during the last round played and the total money accumulated.

Each round ends with a private debriefing interview with the contestant that withdrew or was expelled in which the rankings are revealed and impressions about performance relative to others are discussed.

The financial stakes of the game are quite high. Across rounds, the rewards for correct answers vary from 75 USD (round 1) to 375 USD (round 5). Questions were selected by the organizers to be approximately equal in difficulty across rounds.

Two coders coded all the data by watching replays of all 43 episodes of the game show. Most of the data were easy to obtain and code, (e.g., numbers of correctly answered questions, accumulated gains, and so on). However, others concerning the behavioral attitudes expressed by contestants required subjective judgments made by assigning behaviors to small, discrete categories. The subjective judgments of the two coders were highly correlated. They agreed on $98 \%$ of the codes in the first codification. When they disagreed, they reran the recording of part of a show to reach agreement by consensus. 


\section{Goals and hypotheses}

The substantive question motivating our investigation is whether gender effects disappear in competitive situations when one controls for discriminatory practices and preferences for special considerations such as child rearing. Thus, since we start the games with an approximately equal gender ratio, the null hypothesis is that of no differences in the gender ratio as the game progresses across rounds. If this hypothesis is rejected, what factors can explain any ensuing gender gap?

Our second objective is to characterize winners. Who are the people who manage to stay longer in the game and obtain the largest earnings? Do they behave differently from other contestants?

\section{Results}

As noted above, we report data for six weeks of the show involving 36 regular games and six Sunday games. Of the 216 players, 90 were expelled and 125 left the game voluntarily. The mean payoff that contestants took home was 2,618 USD, with a median of 625 USD. The winner of the final game (a man) earned 29,625 USD. We report general results on the behavior of all contestants first and then describe genderspecific results.

Withdrawals. Table 1 presents the number of people who decided to withdraw in each round (aggregated across all games). We coded as "withdrawal" any attempt to withdraw from the game (i.e., by pushing the decision button), whether it led the contestant to leave the game or not. A contestant who decided to withdraw did not actually leave the game if: (1) several contestants pushed the withdrawal buttons and the contestant was not the first to do so (only the one who pushed the button first leaves the game); or (2) the contestant pushed the button too late, i.e., after the period 
for decisions to be made had ended. The decision to withdraw was taken 155 times in the coded shows. From these 155 decisions, 125 resulted in actual exiting the game.

Insert Table 1 about here

If all players decide to stay in, the base-rate probabilities for being expelled vary by round: $1 / 6$ for round $1 ; 1 / 5$ for round $2 ; 1 / 4$ for round $3 ; 1 / 3$ for round 4 ; and $1 / 2$ for round 5 (last column in Table 1). These probabilities can be used to find the expected number of withdrawals (lower panel of Table 1). All in all, if players were correctly calibrated, there should be one player deciding to exit each round, so that there would be 36 exits per round in 36 regular games, and 6 exits per round in 6 Sunday games.

In fact, in the 36 regular games generally too few people chose to exit, e.g., only 9 and 23 in rounds 1 and 2. Across all rounds of the regular games, there were 108 decisions to withdraw, while the expected number of withdrawals is 180 . However, in the 6 Sunday games, participants attempted to exit the game more often than the base-rate probabilities suggest: there were 42 decisions to exit against 30 expected exits. One explanation for the apparent increase in risk aversion is that accumulated gains were much larger in Sunday as opposed to the regular games (details are provided further below).

Winners. Twenty-five men and 11 women won in the 36 regular games. Of these, 5 men and 1 woman won in Sunday games.

The future winners-to-be already did better than other contestants in the first rounds of regular games. Table 2 details the gains of the eventual winners and other players in the five rounds of regular games. The advantage of performing well early 
in the game is demonstrated by the fact that the difference between the payoffs of the eventual winners and others is statistically significant for all but the fourth rounds. ${ }^{5}$

Insert Table 2 and Figure 1 about here

We next report our main gender-specific results.

Result 1: There is a significant gender gap in earnings.

Women earned significantly less than men: mean earnings were 3,390 USD for men and 1,756 USD for women (52\% relative to men). ${ }^{6}$ The maximum female earnings were 23,550 USD ( $79 \%$ of the male maximum). The median earnings for men were also significantly larger: 936 USD for men vs. 375 USD for women (40\% of the male median).

Result 2: The proportion of women decreases significantly at later stages of the game.

Of the 216 contestants in regular games, 102 were female (47\%). Figure 1 shows that the proportion of female contestants decreased dramatically as the game advanced. That is, in the last round of regular games, 50 of 72 contestants were males $(69 \%)$. In the last round of Sunday games, there were ten men $(83 \%)$ and two women. (In the final game, one woman competed against five men, and in the very last round two men disputed the title of "winner.")

We next analyze possible reasons for the decreasing female/male ratio among contestants. First, it is possible that women were forced out earlier than men from the game due to inferior performance. Second, it is possible that more women withdrew voluntarily from the game than men.

\footnotetext{
${ }^{5}$ This difference is particularly striking when it is recalled that payment for correct answers increased by 75 USD each round.

${ }^{6}$ The difference is statistically significant, Wilcoxon rank-sum test $\mathrm{z}=2.29, \mathrm{p}=0.02, \mathrm{n}=216$.
} 
Result 3: In regular games, more women are expelled than men.

Figure 2 illustrates the percentage of contestants who were expelled from the game at the end of each round due to the lowest ranking, separately for males and females. The percentage of expelled contestants is larger for women than men in the first four rounds of the regular game. Payoffs that male and female contestants accumulated at the end of each round (before being expelled) confirm the pattern of expulsions (Table 3). Female contestants had lower accumulated payoffs than male contestants in the first rounds of regular games. However, in Sunday games there was no significant difference between accumulated payoffs of men and women who remained in the game.

Insert Figure 2 and Table 3 about here

The gender difference in accumulated payoffs in regular games was due to a relatively minor difference in the number of correct answers. Figure 3 depicts the proportion of correct answers separately for men and women in each round of the regular and Sunday games. Although men performed on average better than women in all rounds of the regular games, the gender difference in the proportion of correct answers did not exceed 9 percentage points in the first four rounds. The difference of the proportion of correct answers between male and female contestants is significant in the first and last rounds of regular games (Wilcoxon rank-sum test, $\mathrm{z}=2.34, \mathrm{p}=$ $0.02, \mathrm{n}=216$ and $\mathrm{z}=3.12, \mathrm{p}=0.01, \mathrm{n}=72$, respectively).

Insert Figure 3 about here 
To investigate whether the gender effect in forced expulsions from regular games was due to differences in performance, we performed population-averaged logit analysis $^{7}$ of expulsion ( $1=$ forced out of the game, $0=$ otherwise). The specification included two predictors: gender (female coded as 1) and the proportion of correct answers per round. The controls for the type of game - regular or Sunday and round (indicator variables) were included in the model. Because of multiple observations on individuals (corresponding to multiple rounds), standard errors were calculated accounting for the correlation across repeated observations. The model showed that for each additional $10 \%$ of correct responses the probability of being expelled was 2.1 percentage points smaller $(p<0.01)$. The marginal effect of gender is not statistically significant in this model $(\mathrm{p}>0.10) .{ }^{8}$ This suggests that the gender difference in forced expulsions in regular games was indeed entirely due to differences in performance.

In Sunday games, neither men nor women performed consistently better than the other.

Result 4: There are more voluntary withdrawals from the game among women than among men.

Figure 4 shows the rate of withdrawals by gender. The proportion of contestants who voluntarily withdraw from the game is consistently larger among females. Moreover, the gap increases in Sunday games. In regular games, $6 \%$ of female as opposed to $3 \%$ of male contestants decided to withdraw from the first round. The withdrawal rate increased to $12 \%$ among men and $23 \%$ among women in

\footnotetext{
${ }^{7}$ Population-averaged logistic models were preferred to subject-specific fixed-effects and randomeffects logistic models because our motivation was to examine group-specific effects (i.e., gender effect) rather than subject-specific effects (i.e., distinctive characteristics of each contestant that could make her behavior vary across rounds).

${ }^{8}$ Model $\chi^{2}(7)=51.12,840$ observations, 216 individuals.
} 
the third round, and to $28 \%$ among men and $36 \%$ among women in the last round. In Sunday games, $32 \%$ of men vs. $64 \%$ of women decided to leave the game in the first round and $30 \%$ of men vs. $50 \%$ of women in the last round.

Insert Figure 4 about here

Did women exit the game voluntarily because, having accumulated less gains than men, they would be more likely to be expelled? To answer this question, we fitted a population-averaged logistic model of exit decisions (made in regular and Sunday games) with two predictors: gender (female coded as 1) and accumulated payoff at the moment of the decision. Standard errors were adjusted for the correlation across repeated observations. The model showed that for each additional 1,000 USD of accumulated payoff the probability of withdrawal was 2.2 percentage points larger $(p<0.01)$. The marginal effect of gender was also statistically significant in this model. It indicated that the probability of withdrawal was 6.9 percentage points larger for women than men $(\mathrm{p}<0.05) .{ }^{9}$ Figure 5 depicts predicted probabilities of withdrawal as a function of accumulated payoff, separately for men and women. ${ }^{10}$

Insert Figure 5 about here

All withdrawals can be classified as correct or incorrect decisions. The decisions are classified as correct if a contestant is indeed ranked last and thus would be expelled. Incorrect decisions are taken by contestants who are not ranked last in a

\footnotetext{
${ }^{9}$ Model $\chi^{2}(2)=27.84,840$ observations, 216 individuals.

${ }^{10}$ Of the 36 groups coded, in 8 women were a minority and only in 1 they were a majority. In 15 groups, a woman was expelled in the first round of regular games. We thus also analyzed whether the group composition and early female expulsions affected women's behavior. Logistic models showed that neither group composition nor early female expulsions affected women's decisions to exit the game.
} 
given round. Table 4 shows the percentage of incorrect decisions to withdraw taken by men and women. Table 5 details payoffs to those who actually exited the game and, in addition, foregone payoffs to those expelled from the game.

Insert Tables 4 and 5 about here

Separate logistic models of correct and incorrect exit decisions in regular and Sunday games with gender and accumulated gain as predictors (population-averaged models, standard errors adjusted for repeated observations) showed that the probability of correctly withdrawing from the game was the same for men and women with the same accumulated gains ( $\mathrm{p}$ for female $>0.4$, model $\chi^{2}(2)=10.16,840$ observations, 216 individuals). On the other hand, the probability of incorrect withdrawals was 5 percentage points higher for women than men $(\mathrm{p}>0.05$, model $\left.\chi^{2}(2)=22.99\right)$. Parenthetically, we note that this result is consistent with women being more risk averse than men, having less liking for competition, and possibly also lower expectations of success in the task (cf., Deaux \& Farris, 1977).

Result 5: Female winners-to-be are as active in the interactions as male contestants.

Our more qualitative data revealed that female contestants engaged less in strategic end-of-round interactions (women were "very active" in $43 \%$ of the interactions versus 59\% for men; proportion test $\mathrm{z}=3.17, \mathrm{p}<0.01$ ). However, female winners-to-be were as active in the interactions as male contestants. In particular, female winners-to-be were especially active in $67 \%$ of the interactions of the regular games (versus $37 \%$ for female non-winners; proportion test $\mathrm{z}=-3.09, \mathrm{p}<0.01$ ), while 
male future winners were very active in $58 \%$ of the interactions (versus $60 \%$ for male non-winners; proportion test $\mathrm{z}=0.20, n s)^{11}$

The behavioral difference between female winners-to-be and non-winners explains the overall difference between winners-to-be and non-winners. Across both genders, future winners were more active in the end-of-round interactions of the regular games. Winners-to-be talked "a lot" in $61 \%$ of the interactions compared to $49 \%$ for other contestants (proportion test $\mathrm{z}=-2.06, \mathrm{p}<0.05$ ).

As to persuading others to withdraw from the game, male contestants employed this strategy marginally more than their female counterparts -- in 10\% vs. $6 \%$ of the interactions. The difference, however, is not statistically significant (proportion test $\mathrm{z}=0.60, n s$ ). Within-gender comparisons showed that winners-to-be were not using this strategy more than less successful contestants across rounds.

\section{General Discussion}

The analysis of the game show data clearly rejects the null hypothesis of no gender effects across rounds of the game. Noting that the game starts with approximately the same numbers of males and females, we find, first, that men earn more than women; and second, women exit the game, on average, faster than men. Moreover, whereas this can be explained partly by a performance difference, women also exit voluntarily more than men. At a qualitative level, winning contestants engaged in more strategic bantering (to persuade others to quit) and men tended to do this more than women. Interestingly, although the sample size was smaller, there were no gender differences in the Sunday as opposed to the regular game as measured by the number of correctly answered questions and total accumulated gains. In addition, while women overall

\footnotetext{
${ }^{11}$ The difference between $67 \%$ for female winners-to-be and 59\% for all male contestants is not statistically significant (proportion test $\mathrm{z}=0.92, n s$ ).
} 
engaged less in strategic end-of-round interactions, female winners-to-be were as active in the interactions as male contestants. This suggests, therefore, that those women who won regular games became a self-selecting group who behaved more like the men. Reasons could include effects of positive experience with the task such as reduced risk-aversion, ${ }^{12}$ increased self-confidence, or greater comfort at performing in public. All in all, the "glass ceilings" we observed were not inevitable.

One way to interpret the game is as a metaphor for executives climbing a corporate hierarchy where promotions depend on both relative ability and the willingness to compete with others. At the outset, the corporation recruits approximately the same number of male and female executives of equal ability. Periodically, these executives receive information about their performance and must decide whether this justifies continuing. In other words, the rounds of the game are similar to levels in a corporation where workers have to decide whether to withdraw from competing with their peers or to attempt to climb further. And, similar to life in corporations, if the "weak" don't choose to leave, they are eliminated. At the same time, as in corporate life, the game allows for strategic posturing by competitors.

However, the game differs crucially in one respect from its corporate counterpart. There is no equivalent for gender-specific "constraints" such as child rearing for female participants. That is, in the game women don't differ from men in having an alternative option to pursue. This difference is critical because it means that the glass ceiling we observed cannot be explained by women choosing to pursue a specific, alternative activity.

Drawing parallels between the structure of the game and that of a corporate hierarchy, our results imply that, in such organizations, the advantage of groups (here:

\footnotetext{
${ }^{12}$ In a laboratory study, Gysler, Kruse, and Schubert (2002) found that risk aversion of women in a financial context diminished with experience.
} 
male and female) is cumulative in nature. Thus, any female disadvantage in being promoted to the top level (or winning the competition) has its origin in what happens early in the process. For example, in our data both higher rates of expulsion and voluntary exits for women at earlier stages of the game (i.e., at "lower levels" of the hierarchy) meant that, in the competition for the "top spots," women were a minority.

This insight has important ramifications for promoting gender diversity in organizations. In particular, it's no use bemoaning the lack of good female candidates for senior positions. Instead, it is important to commit resources to maintaining and promoting women at the lower and middle levels so that the ultimate pool of senior female candidates can be as large as that of men.

Our work represents an opportunistic attempt to illuminate an important social problem by capitalizing on a "natural experiment." It is therefore appropriate to assess its strengths and weaknesses. On the positive side, we note, first, that all contestants volunteered to participate in what they knew was a competitive game with a strong public dimension. This is not dissimilar to starting to work in a large corporation although, of course, the game involves even wider dissemination of performance data. Second, payoffs were substantial and especially when one considers the amount of time devoted to the game. Third, as noted above, both discrimination and genderspecific constraints can be ruled out as alternative explanations for the behavior observed.

At the same time, the field nature of this natural experiment suggests care in interpreting results. First, there were small differences in ability (as measured by performance) between men and women in the regular games. Whereas we find controlling statistically - that women still exited the game voluntarily at a higher rate than men, an improved experimental design would have involved equating men and 
women on a number of dimensions before the games even started. Since we are measuring performance, however, controls should not concern just knowledge about the kinds of questions asked but also comfort levels in terms of answering questions in public. Interestingly - and perhaps significantly - those women and men who experienced success and advanced to the Sunday games performed at approximately the same level.

Second, we had no control over how the groups of six participants playing each game were formed and this could have had some effects on outcomes. For example, previous studies have shown that the gender gap in performance in competitive environments is much larger in mixed-sex as opposed to single-sex tournaments (Gneezy, Niederle, \& Rustichini, 2003).

Third, one can question whether it is possible to generalize from performance on general knowledge questions. Clearly, there is a large inferential jump from general knowledge questions to job performance and, as is well known, jobs can have characteristics that are gender related or stereotypical (e.g., nursing). A further consideration is the lack of opportunities for learning to improve performance during the game which, once again, might be gender-related for different types of tasks in naturally occurring environments.

All these disadvantages inherent in our research clearly define questions for further investigation using both more focused experimental designs and other field studies. Assuming, however, that our quasi-experimental results are valid, we believe that the critical question for future investigations lies in identifying which specific socialization practices lead women to impose their own glass ceilings. Although society needs diversity, it is not clear that socialization processes should be homogeneous for both genders. 


\section{References}

Andersen, Steffen, Harrison, Glenn W., Lau, Mortem Igel, and Rutström, Elisabet E. (2008). Risk Aversion in Game Shows, in J.C. Cox and G.W. Harrison (eds.), Risk Aversion in Experiments. Bingley, UK: Emerald, Research in Experimental Economics, Volume 12.

Beetsma, Roel, and Schotman, Peter. (2001). Measuring Risk Attitudes in a Natural Experiment: Data from the Television Game Show Lingo, The Economic Journal, 111, 821-848.

Bertrand, Marianne, and Hallock, Kevin F. (2001). The Gender Gap in Top Corporate Jobs. Industrial and Labor Relations Review, 55, 3-21.

Blavatskyy, Pavlo, and Pogrebna, Ganna. (2008). Risk Aversion When Gains Are Likely and Unlikely: Evidence from a Natural Experiment with Large Stakes. Theory and Decision, 64, 395-420.

Blau, Francine, and Kahn, Lawrence M. (2000). Gender Differences in Pay, Journal of Economic Perspectives, 14(4), 75-99.

Bowles, Hannah Riley, Babcock, Linda, and Lai, Lei. (2007). Social Incentives for Gender Differences in the Propensity to Initiate Negotiations: Sometimes It Does Hurt to Ask. Organizational Behavior and Human Decision Processes 103, 84-103.

Daghofer, Fedor. (2007). Financial Risk-Taking on "Who Wants To Be a Millionaire": A Comparison between Austria, Germany, and Slovenia. International Journal of Psychology, 42 (5), 317-330.

Deal, Jennifer J. (2000). Gender Differences in the Intentional Use of Information in Competitive Negotiations. Small Group Research, 31(6), 702-723.

Deaux, Kay, and Farris, Elizabeth. (1977). Attributing Causes for One's Own Performance: The Effects of Sex, Norms, and Outcome. Journal of Research in Personality, 11/1, 59-72.

Gertner, Robert. (1993). Game Shows and Economic Behavior: Risk-Taking on "Card Sharks". The Quarterly Journal of Economics, 108(2), 507-521. 
Gneezy, Uri, Leonard, Kenneth L., and List, John A. (2008) Gender Differences in Competition: Evidence from a Matrilineal and a Patriarchal Society. Forthcoming in Econometrica.

Gneezy, Uri, Niederle, Muriel, and Rustichini, Aldo. (2003). Performance in Competitive Environments: Gender Differences. The Quarterly Journal of Economics, 118(3), 1049-1074.

Gysler, Matthias, Kruse, Jamie Brown, and Schubert, Renate. (2002). Ambiguity and Gender Differences in Financial Decision Making: An Experimental Examination of Competence and Confidence Effects. Working paper, Center for Economic Research, Swiss Federal Institute of Technology.

Johnson, Daniel K. N., and Gleason, Tracy R. (in press). Who REALLY Wants To Be a Millionaire: Gender Differences in Game Show Contestant Behavior Under Risk. Social Sciences Quarterly.

Kray, Laura J., and Thompson, Leigh. (2005). Gender stereotypes and negotiation performance: A review of theory and research. In B. Staw \& R. Kramer (Eds.), Research in Organizational Behavior Series, 26, 103-182.

Larkin, Judith E., and Pines, Harvey A. (2003). Gender and risk in public performance. Sex Roles, 49, 197-210.

Lyness, Karen S., and Heilman, Madeline E. (2006). When Fit is Fundamental: Performance Evaluations and Promotions of Upper-Level Female and Male Managers. Journal of Applied Psychology, 91(4), 777-785.

Martell, R. F., Lane, D. M., and Emrich, C. (1996). Male-female differences: A computer simulation. American Psychologist, 51, 157-158.

Martin, C. L., \& Halverson, C. F. (1981). A schematic processing model of sex typing and sex stereotyping in children. Child Development, 52, 1119-1134.

Martin, C. L., Wood, C. H., \& Little, J. K. (1990). The development of gender stereotype components. Child Development, 61, 1891-1904.

Metrick, Andrew. (1995). A Natural Experiment in 'Jeopardy!'. American Economic Review, 85(1), 240-253.

Mulino, Daniel, Scheelings, Richard, Brooks, Robert, and Faff, Robert. (2006) An Empirical Investigation of Risk Aversion and Framing Effects in the Australian 
Version of Deal Or No Deal." Working Paper, Department of Economics, Monash University.

Niederle, Muriel, and Vesterlund, Lise. (2007). Do Women Shy Away from Competition? Do Men Compete Too Much? The Quarterly Journal of Economics, 122(3), 1067-1101.

Pogrebna, Ganna. (2008). Naïve Advice When Half a Million is at Stake. Economics Letters, 98, 148-154.

Post, Thierry, van den Assem, Martin J., Baltussen, Guido, and Thaler, Richard H. (2008). Deal or No deal? Decision Making under Risk in a Large-Payoff Game Show. American Economic Review, 98(1), 38-71.

Rubin, Jeffrey Z., and Brow, Bert R. (1975). The Social psychology of bargaining and negotiation. New York: Academic Press.

Wood, Robert, Corcoran, Mary, and Courant, Paul. (1993). Pay Differences among the Highly Paid: The Male-Female Earnings Gap in Lawyers' Salaries. Journal of Labor Economics, 11(3), 417-441. 
$\underline{\text { Table 1: Actual and expected number of withdrawals }}$

\begin{tabular}{|c|c|c|c|c|}
\hline \multicolumn{4}{|c|}{$\begin{array}{l}\text { Actual number of withdrawals* } \\
\text { (Total number of participants) }\end{array}$} & \multirow{2}{*}{$\begin{array}{l}\text { Base-rate } \\
=\text { probability for } \\
\text { being expelled }\end{array}$} \\
\hline Round & $\begin{array}{l}\text { Regular } \\
\text { games }\end{array}$ & $\begin{array}{l}\text { Sunday } \\
\text { games }\end{array}$ & $\begin{array}{l}\text { The } \\
\text { Final }\end{array}$ & \\
\hline 1 & $\begin{array}{l}9 \\
(216)\end{array}$ & $\begin{array}{l}15 \\
(36)\end{array}$ & $\begin{array}{l}1 \\
(6)\end{array}$ & 0.17 \\
\hline 2 & $\begin{array}{l}23 \\
(180)\end{array}$ & $\begin{array}{l}8 \\
(30)\end{array}$ & $\begin{array}{l}2 \\
(5)\end{array}$ & 0.20 \\
\hline 3 & $\begin{array}{l}24 \\
(144)\end{array}$ & $\begin{array}{l}8 \\
(24)\end{array}$ & $\begin{array}{l}1 \\
(4)\end{array}$ & 0.25 \\
\hline 4 & $\begin{array}{l}30 \\
(108)\end{array}$ & $\begin{array}{l}7 \\
(18)\end{array}$ & $\begin{array}{l}1 \\
(3)\end{array}$ & 0.33 \\
\hline 5 & $\begin{array}{l}22 \\
(72) \\
\end{array}$ & $\begin{array}{l}4 \\
(12) \\
\end{array}$ & $\begin{array}{l}0 \\
(2) \\
\end{array}$ & 0.50 \\
\hline Total & $\begin{array}{l}108 \\
(720)\end{array}$ & $\begin{array}{l}42 \\
(120)\end{array}$ & $\begin{array}{l}5 \\
(20)\end{array}$ & \\
\hline
\end{tabular}

Expected number of withdrawals

$\begin{array}{rlll}\text { Per round } & 36 & 6 & 1 \\ \text { Total } & 180 & 30 & 5\end{array}$

*including the decisions to withdraw both resulting in actual exits and not 
Table 2: Mean accumulated gains to winners-to-be and other players after different $\underline{\text { rounds in regular games }}$

\begin{tabular}{cllll} 
Round & Winners & Others & z \\
\hline \hline & Gains & $\mathrm{n}$ & Gains & $\mathrm{n}$ \\
&
\end{tabular}

$\underline{\text { Regular games }}$

$\begin{array}{lrlrll}1 & 471 & 36 & 388 & 180 & -4.07 * * * \\ 2 & 913 & 36 & 784 & 144 & -3.36 * * * \\ 3 & 1,506 & 36 & 1,227 & 108 & -2.45 * \\ 4 & 2,423 & 36 & 2,268 & 72 & -1.47 \\ 5 & 3,631 & 36 & 3,244 & 36 & -2.55 *\end{array}$

Notes: $\quad$ z: Two-sample Wilcoxon rank-sum test $* * * \mathrm{p}<0.001 ; * * \mathrm{p}<0.01 ; * \mathrm{p}<0.05$. 
Table 3: Mean accumulated gains in regular and Sunday games

\begin{tabular}{|c|c|c|c|c|}
\hline Round & Men & & Women & \\
\hline & Gains & $\mathrm{n}$ & Gains & $\mathrm{n}$ \\
\hline
\end{tabular}

$\underline{\text { Regular games }}$

$\begin{array}{lrlrlrl}1 & 419 & 114 & 383 & 102 & 2.34 & * \\ 2 & 842 & 98 & 772 & 82 & 2.22 & * \\ 3 & 1,439 & 83 & 1,297 & 61 & 2.09 & * \\ 4 & 2,394 & 71 & 2,177 & 37 & 1.70 & \\ 5 & 3,659 & 50 & 2,935 & 22 & 3.42 & * * *\end{array}$

Sunday games

$\begin{array}{lrlrll}1 & 8,481 & 25 & 8,339 & 11 & 0.96 \\ 2 & 9,414 & 23 & 9,568 & 7 & -0.69 \\ 3 & 10,512 & 19 & 11,130 & 5 & -1.35 \\ 4 & 12,045 & 14 & 11,950 & 4 & 0.05 \\ 5 & 14,650 & 10 & 14,825 & 2 & -0.11\end{array}$

Notes: z: Two-sample Wilcoxon rank-sum test $* * * \mathrm{p}<0.001 ; * * \mathrm{p}<0.01 ; * \mathrm{p}<0.05$. 
Table 4: Percentage of incorrect decisions to withdraw among men and women

\begin{tabular}{ccc} 
Round & Men & Women \\
\hline \hline
\end{tabular}

Regular games:

$\begin{array}{lll}1 & 0 \% & 100 \% \\ 2 & 64 \% & 42 \% \\ 3 & 40 \% & 71 \% \\ 4 & 44 \% & 58 \% \\ 5 & 50 \% & 25 \%\end{array}$

Sunday games:

$\begin{array}{lll}1 & 75 \% & 71 \% \\ 2 & 80 \% & 33 \% \\ 3 & 67 \% & 50 \% \\ 4 & 40 \% & 50 \% \\ 5 & 33 \% & 0 \%\end{array}$


Table 5: Payoffs by type of exit and gender

Payoffs (\$) to: $\quad$ Withdrawals*:

Expulsions

(foregone payoff):

\begin{tabular}{|c|c|c|c|c|c|c|}
\hline Round & Men & & Women & & Men & Wome \\
\hline & correct & incorrect & correct & incorrect & & \\
\hline \multicolumn{7}{|c|}{ Regular games: } \\
\hline 1 & 300 & - & - & 330 & 294 & 255 \\
\hline 2 & 675 & 725 & 613 & 750 & 700 & 578 \\
\hline 3 & 1,000 & 1,088 & 863 & 1,283 & 938 & 1,180 \\
\hline 4 & 2,058 & 2,363 & 1,900 & 2,575 & 1,875 & 1,763 \\
\hline 5 & 3,214 & 3,695 & 3,000 & 3,038 & 3,327 & 2,681 \\
\hline
\end{tabular}

Sunday games:

$\begin{array}{lllllll}1 & - & 8,400 & 7,725 & 8,175 & - & - \\ 2 & 8,625 & 9,600 & 8,775 & - & - & 9,300 \\ 3 & 10,575 & 10,450 & - & 10,350 & 9,675 & - \\ 4 & 11,575 & 11,488 & 10,700 & 12,700 & - & - \\ 5 & 12,913 & 15,825 & 14,450 & - & 14,950 & -\end{array}$

$\begin{array}{llllll}\text { Mean } & \underline{5,659} & \underline{7,070} & \underline{6,003} & \underline{4,900} & \underline{4,537}\end{array}$

* only withdrawals resulting in actual exits 
Figure 1: Proportions of men and women as the game advances

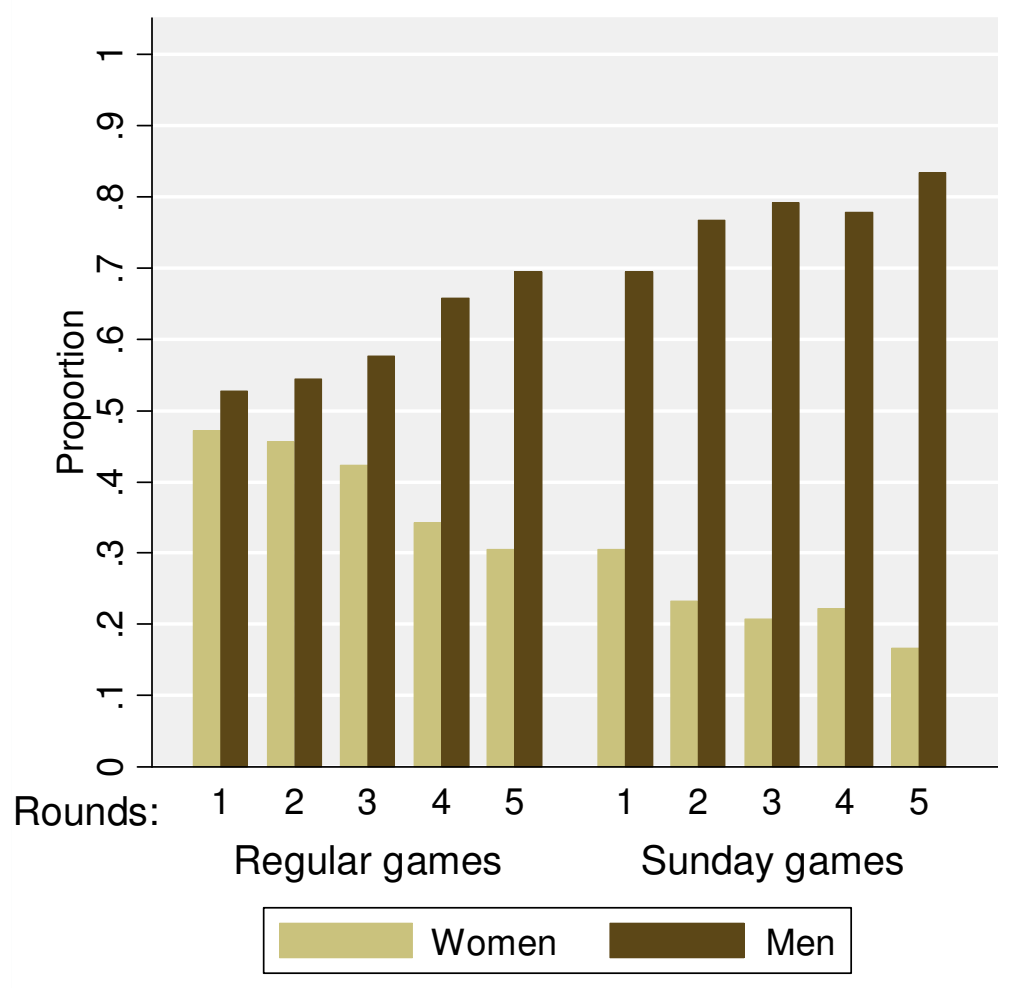


Figure 2: Percentage of contestants expelled from the game - by gender

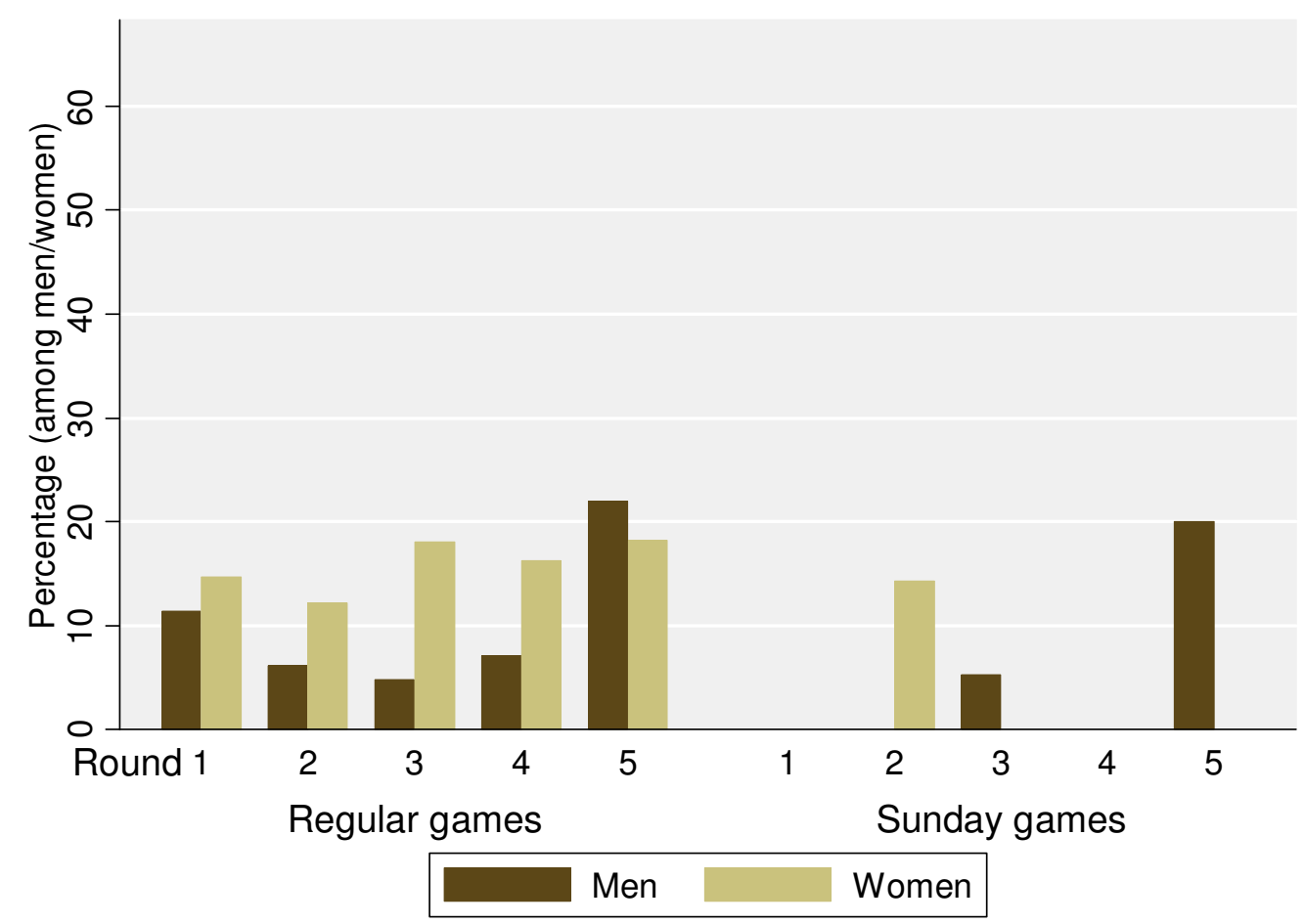


Figure 3: Proportion of correct answers in regular and Sunday games - by gender

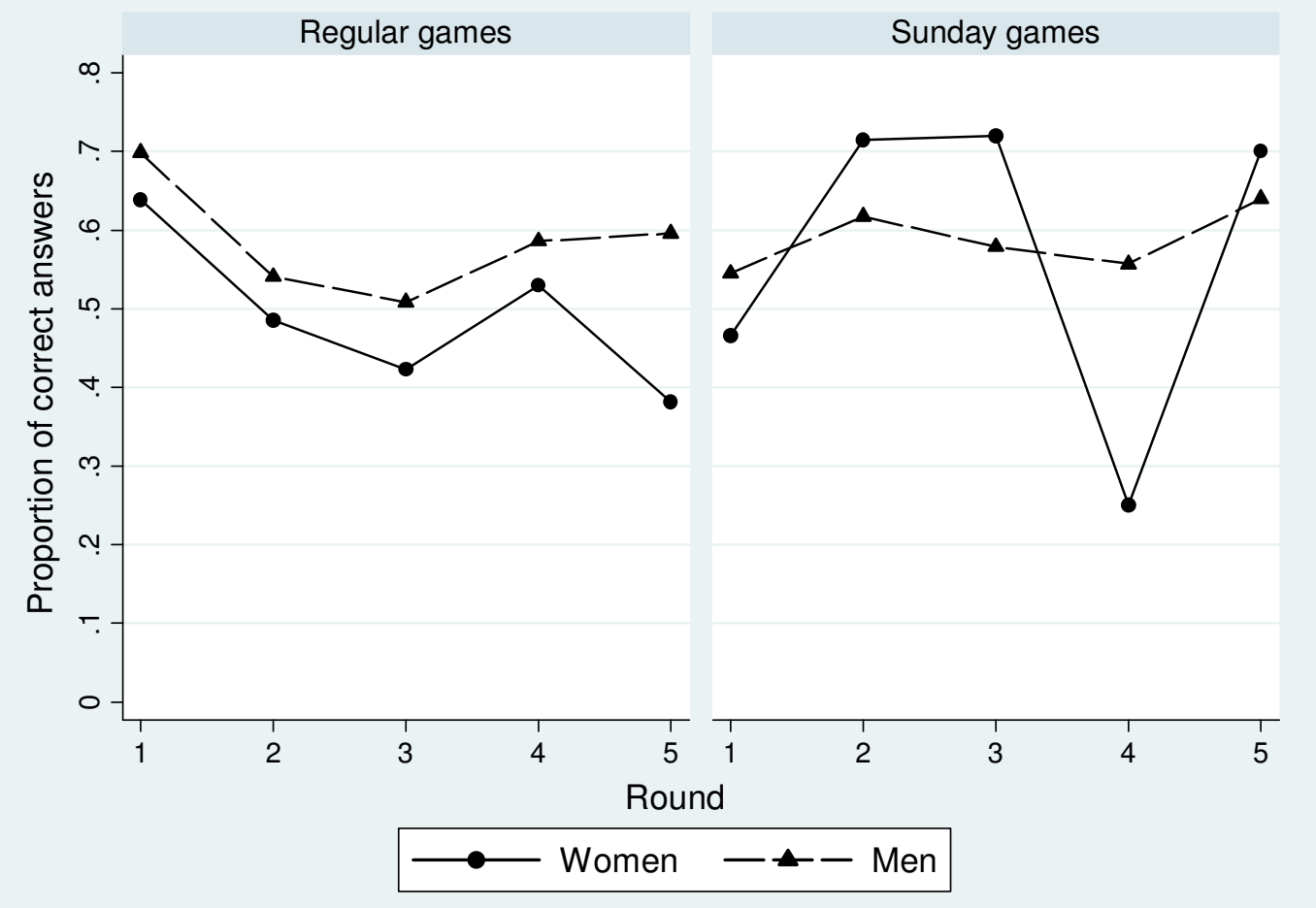


Figure 4: Percentage of contestants who decided to withdraw from the game - by gender

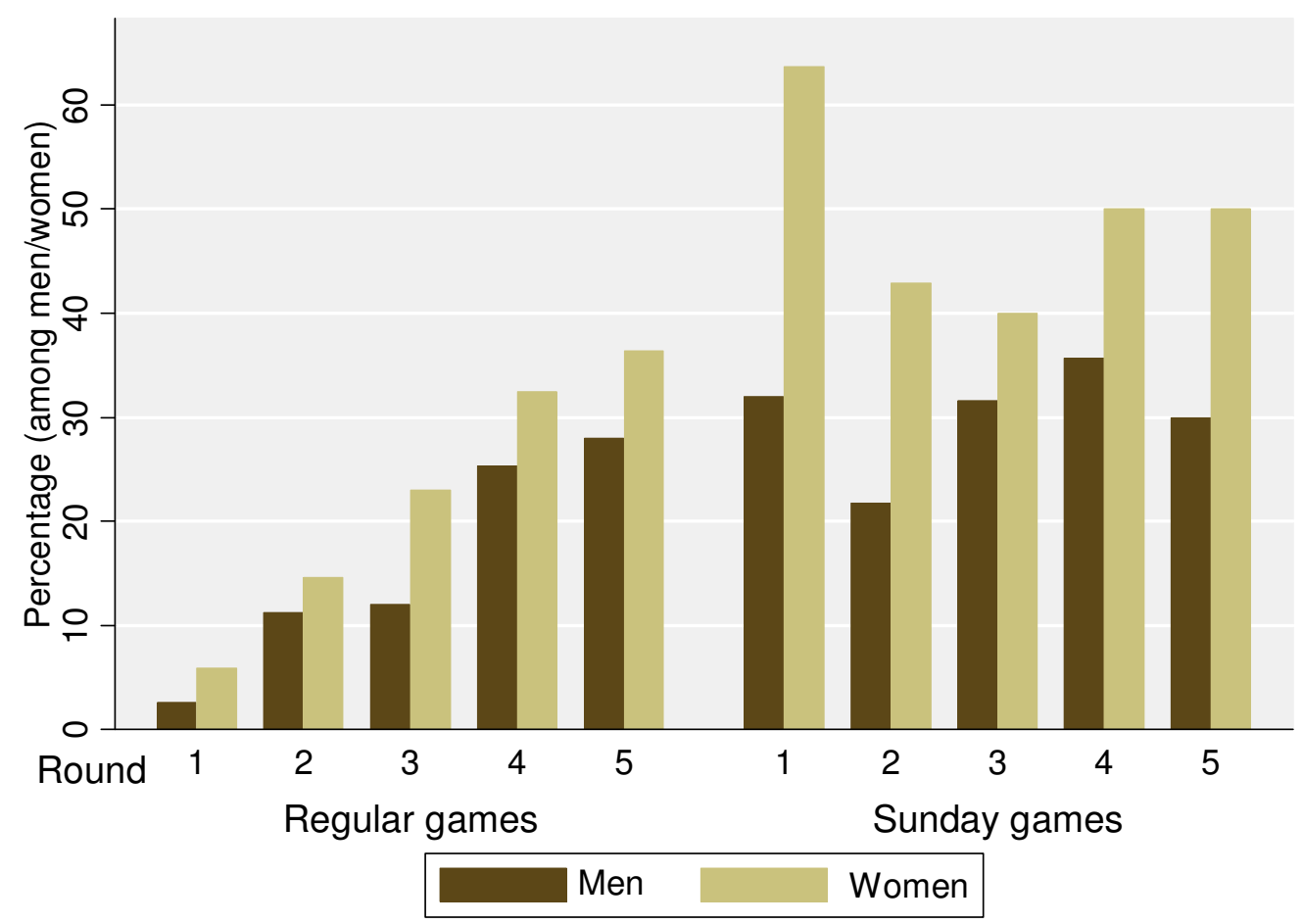


Figure 5: Predicted probabilities of withdrawal - by gender

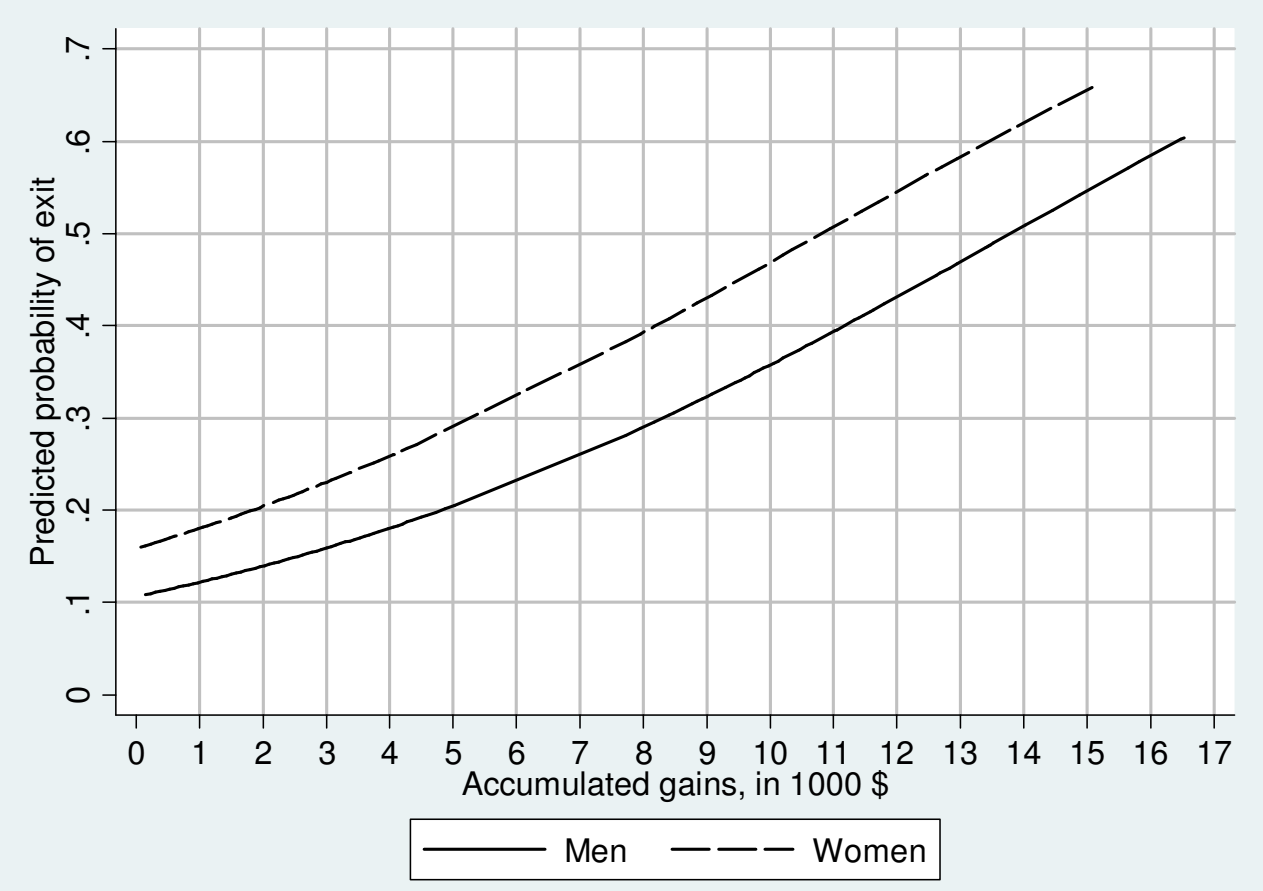

